\title{
N-Methyl-D-Aspartate Receptor-Induced, Inherent Oscillatory Activity in Neurons Active During Fictive Locomotion in the Lamprey
}

\author{
P. Wallén and S. Grillner \\ Nobel Institute for Neurophysiology, Karolinska Institutet, S-104 01 Stockholm, Sweden
}

Bath application of $\mathbf{N}$-methyl-aspartate induces fictive locomotor activity in the isolated spinal cord preparation of the lamprey, as well as TTX-resistant membrane potential oscillations in many individual neurons. This inherent oscillatory activity is shown to depend on a specific activation of $\mathrm{N}$-methyl-D-aspartate (NMDA) receptors. This activation initiates voltage-dependent, magnesium-requiring membrane potential bistability, presumably due to a development of a region of negative slope conductance in the currentvoltage relation of the neuron. When sodium ions were removed from the bathing solution, oscillations disappeared, and the membrane potential was maintained at a hyperpolarized level, suggesting that the depolarizing current during the oscillatory cycle is mainly carried by sodium ions. Replacing $\mathrm{Ca}^{2+}$ with $\mathrm{Ba}^{2+}$ also leads to a cessation of oscillatory activity, with the membrane potential remaining at the more depolarized level. This indicates an involvement of a $\mathrm{Ca}^{2+}$ dependent $\mathrm{K}^{+}$current during the repolarization phase. These findings, together with the voltage dependence, can account for the main characteristics of the NMDA receptor-induced, TTX-resistant membrane potential oscillations. This oscillatory behavior has been demonstrated in motoneurons and in several interneurons including $\mathrm{CC}$ interneurons but has not been found in edge cells, dorsal cells, or lateral interneurons. The possibility that inherent oscillatory membrane properties may contribute to the activity pattern during fictive locomotion was investigated in experiments with intracellular current injection in the absence of TTX. The stimulation effects obtained required the presence of magnesium ions and were analogous to the stimulation effects seen during oscillations after TTX blockade. Together with similarities in, for instance, frequency and amplitude between the locomotor oscillatory activity and the TTX-resistant oscillations, the results are compatible with an involvement of inherent, oscillatory membrane properties during fictive locomotion in the lamprey spinal cord.

The neuronal mechanisms underlying rhythmic motor acts have been successfully investigated in several "simple" preparations (e.g., Kristan and Weeks, 1983; Selverston and Moulins, 1985; Getting, 1986; Roberts et al., 1986). The CNS of the lamprey,

\footnotetext{
Received Dec. 9, 1986; revised Feb. 27, 1987; accepted Mar. 2, 1987.

We gratefully acknowledge the valuable comments on the manuscript from Drs. L. E. Moore and L. Brodin, as well as the skillful assistance of Ms. H. Axegren and Mrs. I. Klingebrant. This study was supported by the Swedish Medical Research Council (Proj. No. 3026) and Karolinska Institutets fonder.

Correspondence should be addressed to P. Wallén, Nobel Institute for Neurophysiology, Karolinska Institutet, Box 60400 , S-104 01 Stockholm, Sweden.

Copyright (C) 1987 Society for Neuroscience 0270-6474/87/092745-11\$02.00/0
}

a primitive vertebrate, is a suitable model system for detailed study of the cellular bases of locomotion in vertebrates (Grillner et al., 1987b). In the isolated preparation of the lamprey spinal cord, fictive locomotor activity can be induced by pharmacological activation of certain excitatory amino acid receptors: the $N$-methyl-D-aspartate (NMDA) receptor and the kainate receptor but not the quisqualate receptor (Grillner et al., 1981; Brodin et al., 1985; cf. Watkins and Evans, 1981; Davies and Watkins, 1983). Not only does bath application of agonists for NMDA and kainate receptors evoke fictive locomotion, but specific antagonists will also block naturally initiated locomotor activity (e.g., spontaneously occurring or caused by sensory stimulation). Activation of these amino acid receptors thus appears to be a prerequisite for the occurrence of locomotor activity under normal conditions (Brodin and Grillner, 1985a, b). Unitary synaptic potentials elicited by an activation of NMDA and kainate/ quisqualate receptors have recently been described in the lamprey spinal cord (Dale and Grillner, 1986), and furthermore it has been found that spinal interneurons acting via these excitatory amino acid receptors are of primary importance during fictive locomotion (Buchanan and Grillner, 1987; Dale, 1986).

During fictive locomotion, many rhythmically active spinal neurons display well-developed membrane potential oscillations, phase-locked to the efferent ventral root bursts. In myotomal motoneurons the depolarizing peaks of the potential fluctuations occur in phase with the ipsilateral ventral root discharge (Russell and Wallén, 1980, 1983; Buchanan and Cohen, 1982). They are due to synaptic activation of excitatory amino acid receptors of both the NMDA and kainate type (Dale, 1986).

In the search for synaptic as well as nonsynaptic mechanisms (cf. Wallén et al., 1984) that may be of importance in the generation of locomotor activity, it was found that in the presence of an NMDA-receptor agonist, certain spinal neurons continued to show an oscillatory membranc potential even after TTX blockade of the normal, spike-mediated synaptic interactions (Sigvardt and Grillner, 1981; Sigvardt et al., 1985). These pacemaker-like membrane potential oscillations are reset by injected current pulses and are strongly affected by applied DC currents (Wallén and Grillner, 1985). They are thus likely to be due to inherent properties of the individual neuron (Wallén and Grillner, 1985). The TTX-resistant oscillations depend on an activation of NMDA receptors and require the presence of $\mathrm{Mg}^{2+}$ ions (Grillner and Wallén, 1985). In the absence of $\mathrm{Ca}^{2+}$ ions, the membrane potential oscillations disappear and the cells remain depolarized (Grillner and Wallén, 1985).

Using voltage-clamp techniques, it has been shown that NMDA-receptor activation induces a region of negative slope conductance in the current-voltage relationship of neurons in mammals (MacDonald et al., 1982; Flatman et al., 1983, 1986; 
Mayer and Westbrook, 1984), as well as in lamprey (Moore et al., 1986). A negative slope conductance is found in cells with pacemaker-like membrane potential oscillations (Smith et al., 1975) and in cells with a bistable membrane potential. The development of a region of negative slope conductance after activation of NMDA receptors is due to a voltage-dependent block of an inward current, carried mainly by sodium ions. The channel block results from the presence of $\mathrm{Mg}^{2+}$ ions at a physiological level (Mayer et al., 1984; Nowak et al., 1984; Mayer and Westbrook, 1985). The $\mathrm{Mg}^{2+}$ ions are removed from the channel at more depolarized membrane potential levels (Mayer and Westbrook, 1987). The TTX-resistant oscillations observed in lamprey neurons probably result from similar, bistable membrane properties. Not only do they show a marked voltage dependence, they also require the presence of magnesium, and they are associated with a negative slope conductance (Moore et al., 1986). The aim of this paper is to describe the nature and possible significance of this oscillatory behavior in lamprey neurons. Preliminary reports of some aspects of the TTX-resistant membrane potential oscillations have appeared (Grillner and Wallén, 1985; Wallén and Grillner, 1985).

\section{Materials and Methods}

Experiments were performed on isolated spinal cord pieces from the North American silver lamprey, Ichthyomyzon unicuspis (length, 15$25 \mathrm{~cm}$ ) obtained from Iowa. Pieces of spinal cord (4-16 segments in length) were dissected out from the rostral half of the animal under MS222 anesthesia (100 mg/liter), freed from the notochord, and placed ventral side up in a Sylgard-lined chamber containing cooled $\left(6-9^{\circ} \mathrm{C}\right)$ and oxygenated physiological solution. The technique utilized for preparing the totally isolated spinal cord has been detailed elsewhere (Wallén et al., 1985). Experiments were performed during the first and often also during the second day after dissection. The chamber was continuously perfused with the aid of a circulation pump, and the composition of the bathing solution could be altered during recording. In most cases the control physiological solution contained (in mM): $91 \mathrm{NaCl}, 2.1 \mathrm{KCl}$, $2.6 \mathrm{CaCl}_{2}, 1.8 \mathrm{MgCl}_{2}, 20 \mathrm{NaHCO}_{3}, 4$ glucose, and was bubbled with $95 \% \mathrm{O}_{2}, 5 \% \mathrm{CO}_{2}$ to obtain a pH of about 7.4. In experiments with $\mathrm{Na}^{+}$ removal, the following control physiological solution was instead used (in mM): $96 \mathrm{NaCl}, 2.1 \mathrm{KCl}, 2.6 \mathrm{CaCl}_{2}, 1.8 \mathrm{MgCl}_{2}, 15$ Tris-buffer $(\mathrm{pH}$ 7.76 at $5^{\circ} \mathrm{C}$ ), and 4 glucose, bubbled with $100 \% \mathrm{O}_{2}$. $\mathrm{Na}^{+}$-free solution was prepared by replacing $\mathrm{NaCl}$ with equimolar amounts of Tris-buffer. In some experiments $\mathrm{MgCl}_{2}$ was omitted in order to study the activity under "Mg-free" conditions. In other experiments $\mathrm{CaCl}_{2}$ was omitted or was replaced by $\mathrm{BaCl}_{2}$ in equimolar amounts. To induce fictive locomotor activity as well as TTX-resistant membrane potential oscillations, NMDA or $N$-methyl-D,L-aspartate (NMA) was added to a final concentration of 50-300 $\mu \mathrm{M}$ (most commonly $150 \mu \mathrm{M}$ ). To block action potentials, TTX was added to the perfusion medium (usually $3 \mu \mathrm{M}$ ). Thus, unless stated otherwise, all solutions contained NMA and TTX.

Fictive locomotor burst activity was recorded from the cut ventral roots, which were sucked into glass tip suction electrodes. Intracellular recordings were made with conventional microelectrodes, filled with Lucifer yellow $\mathrm{CH}(5 \%$ in $0.3 \mathrm{M} \mathrm{LiCl})$ or, in some cases, $\mathrm{K}$-citrate $(3 \mathrm{M})$ or K-acetate ( 3 or $4 \mathrm{M}$ ). Results obtained were the same using either electrolyte. Intracellular stimulation (DCand/or pulses) was given through the recording electrode or, in a few cases, via a second microelectrode placed in the same neuron. The contours of recorded cells could generally be visualized during the experiment using transillumination from below. The different types of recorded neurons were identified morphologically after iontophoretic filling with Lucifer yellow and after dehydration, clearing, and mounting of the preparation as a whole mount (cf. Stewart, 1978; Wallén et al., 1985). Motoneurons could also be identified physiologically by recording the time-locked ventral root unit, and $\mathrm{CC}$ interneurons (with axons projecting caudally in the contralateral half of the spiral cord) were identified by recording the axon spike in the contralateral, caudal end of the spinal cord (cf. Buchanan, 1982). The different records were stored on FM tape and on a Mingograf inkwriter for subsequent analysis. The described effects were generally confirmed in at least 3 neurons. An oscilloscope with a UV paper recorder (Medelec) was utilized for preparing illustrations.

\section{Results}

\section{General characteristics of $T T X$-resistant membrane potential} oscillations

If the normal action potential-mediated synaptic interactions are blocked by the addition of TTX, the ventral root bursts occurring during NMA-evoked fictive locomotion will, as expected, decrease in amplitude and eventually disappear. If all aspects of the pattern of membrane potential oscillations were caused by synaptic input, one could predict that all signs of membrane potential oscillations would also disappear. This is what happens in many cells $(60 / 156)$, although this group does not represent a random selection of neurons. In the majority of neurons (96/156), however, the synaptic "noise" disappears, but the cell continues to oscillate (Fig. 1A; Sigvardt and Grillner, 1981; Sigvardt et al., 1985), either "spontaneously" (25/96) or in response to a weak de- or hyperpolarizing DC-current injection. Figure $1 A: 1$ shows a recording from a neuron during NMAinduced fictive locomotion, i.e., before TTX administration, with membrane potential depolarizations and spiking occurring in phase with the ipsilateral ventral root burst. After TTX application the cell spontaneously continued to produce potential oscillations without DC-current stimulation (Fig. 1A:2). A general depolarization occurred during the TTX application in this case, and at this potential level the oscillation frequency was higher (about $2 \mathrm{~Hz}$ ) than during fictive locomotion $(A: 1)$. Upon injection of a weak hyperpolarizing DC current, however, the oscillations slowed to a frequency similar to that before TTX application and, in addition, increased in amplitude (Fig. 1A:3; compare $A: 1)$. The TTX-resistant oscillations can thus be of similar amplitude and frequency as hefore addition of the blocker, i.e., during fictive locomotion. Their shape is, however, modified to a smaller or larger degree (Fig. 1, $A: 1$, 3; see also Sigvardt et al., 1985).

The level of membrane potential at which the TTX-resistant uscillations appear is similar to that during fictive locomotion (Fig. 1). It is also evident that the TTX-resistant oscillations are powerfully influenced by alterations of the average membrane potential level (Fig. 1 $A$ ). To further investigate this potential dependence while maintaining an accurate measure of membrane potential, some neurons were penetrated with 2 microelectrodes, one for passing DC current and the other for recording membrane potential. In the case illustrated in Figure 1, $B, C$, oscillations appeared between approximately 70 and 40 $\mathrm{mV}$ of membrane potential. Figure $1, B: 1$ shows that when the cell was hyperpolarized to just below $40 \mathrm{mV}$ (note dashed line), small-amplitude oscillations appeared. No oscillations occurred at more depolarized levels in this case. Upon increasing hyperpolarizing current injection (Fig. 1, B:2-5), the depolarizing peaks became more well developed (cf. Fig. 1, $A: 2-3$ ), while their frequency decreased. At membrane potentials below about 70 $\mathrm{mV}$, oscillation peaks occurred at long and less regular intervals and eventually ceased (Fig. 1, B:5). This cell displayed its most stable oscillatory activity at potential levels between 44 and 67 $\mathrm{mV}$ (measured at the most negative point between depolarization peaks). Figure $1 C$ illustrates the relationship between membrane potential and cycle period of the oscillations in this range. The voltage dependence of the oscillatory activity is evident; at more hyperpolarized levels, the period length of the oscillation cycle increased markedly. 


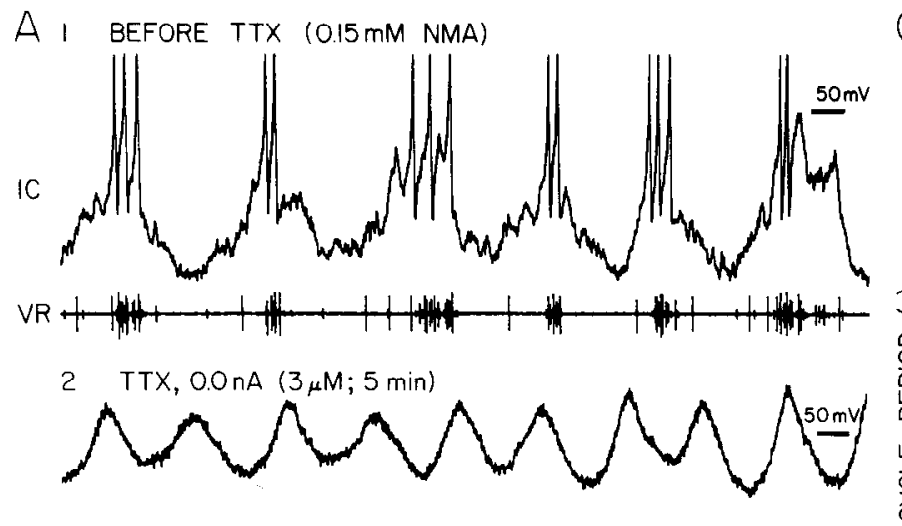

3 TTX, - O.4 nA

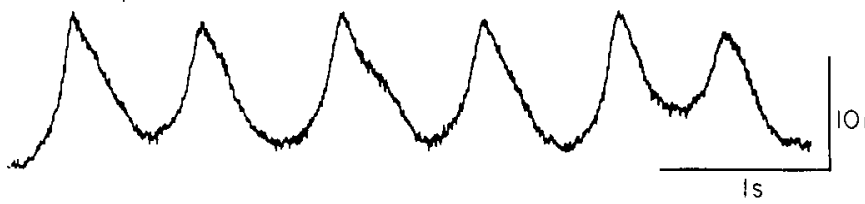

2
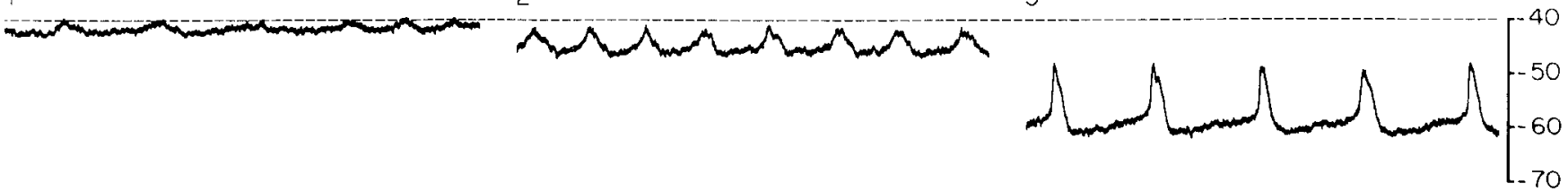

5

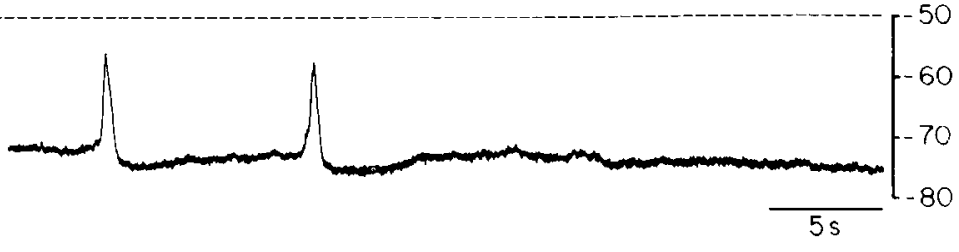

Figure 1. A, Occurrence of TTX-resistant, voltage-dependent membrane potential oscillations in lamprey neurons. 1 , Before TTX blockade, bath application of NMA elicited fictive locomotion: rhythmic bursts of activity in the ventral root (VR) and in phase oscillations and spiking in the neuron as seen from the intracellular trace (IC; spikes have been truncated). 2, After addition of TTX ( $3 \mu \mathrm{M})$, and with NMA still present, activity ceased in the ventral root while the membrane potential continued to oscillate without current injection. Note $-50 \mathrm{mV}$ membrane potential level indications in 1-2. In this cell a general depolarization had occurred between 1 and 2 . The range of membrane potential spanned by the oscillations during fictive locomotion (1) was approximately $65-50 \mathrm{mV}$, and after TTX blockade (2) about $55-45 \mathrm{mV}$. 3, Upon injection of $-0.4 \mathrm{nA}$ DC current, oscillation frequency decreased while the amplitude became larger. Time and voltage calibrations in 3 apply to all records in $A$. $B-C$, Records from another neuron that was penetrated with 2 separate microelectrodes, one for current injection and the other for recording. This cell did not spontaneously oscillate without current injection. When hyperpolarizing DC current was applied $(B)$, small-amplitude oscillations started to appear as the membrane potential level passed below $-40 \mathrm{mV}$ (dashed line in $B: 1-3$ ). When current strength was increased (up to $-4.1 \mathrm{nA}$ in this cell), the period of the oscillatory cycle was prolonged $(B: 2-4)$, while the amplitude of the depolarization pcaks incrcascd. At potential levels below about $-70 \mathrm{mV}$, oscillations became irregular and eventually ceased $(B: 5)$. Time and membrane potential ( $\mathrm{mV}$ ) are indicated to the right. $C$, Relationship between membrane potential (abscissa), measured at the most negative point between depolarization peaks, and the period length of the oscillatory cycle for the neuron in $B$ (ordinate). Mean values \pm SEM except at $54 \mathrm{mV}$, which is a single value.

\section{Dependence on NMDA-receptor activation}

To test if the TTX-resistant membrane potential oscillations are due to a specific activation of NMDA receptors, a specific blocker, 2-amino-phosphono-valerate (2-APV; Davies et al., 1981), was administered to the bath while recording from an oscillating neuron in the presence of TTX and a constant level of NMA (Fig. 2). 2-APV first caused a decrease of oscillation frequency and eventually a total cessation of oscillatory activity (Fig. $2 B$ ). The membranc potential then remained flat at a hyperpolarized level (note the dashed lines in Fig. 2, $A, B$, indi- cating the hyperpolarized potential level of the control oscillations). When 2-APV was removed from the perfusion solution, the oscillations reappeared with peaks depolarizing from the previously constant potential level (Fig. 2C). Thus, blockade of the NMDA receptors causes a cessation of the membrane potential oscillations, which therefore appear to depend on an activation of this type of receptor. Accordingly, removal of the agonist NMA from the medium will make the oscillations decrease in frequency and amplitude, and they will eventually disappear (Fig. 2, D, E; Sigvardt et al., 1985).

Having established that the membrane potential oscillations 
A

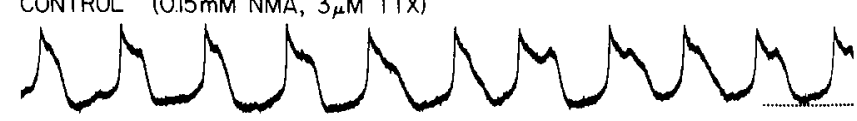

B ADD. $20 \mu \mathrm{M}$ 2-APV
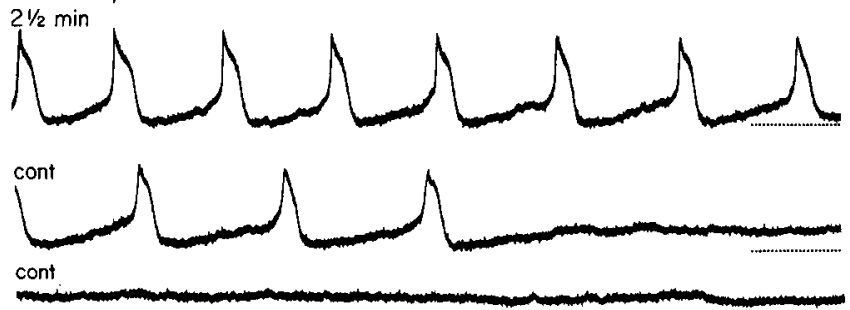

C WASH-OUT $(0.15 \mathrm{mM} \mathrm{NMA,} 3 \mu \mathrm{M}$ TTX)

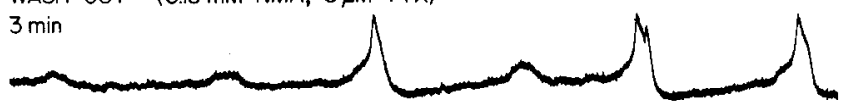

cont

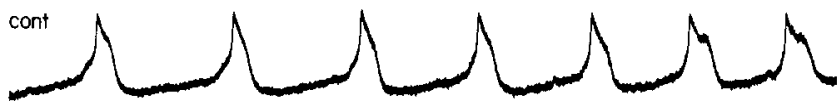

D CONTROL (O.I5 mM NMA. $3 \mu \mathrm{M}, \mathrm{IX})$

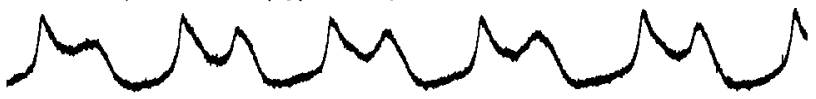

E WASH-OUT $\left(3_{\mu} M\right.$ TTX)

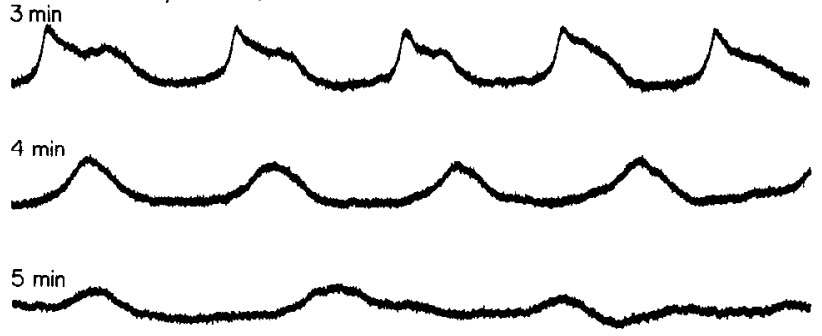

$6 \min$

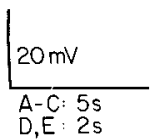

Figure 2. Dependence on NMDA-receptor activation for the induction of TTX-resistant membrane potential oscillations. Upon addition of the specific NMDA-receptor blocker 2-APV $(B)$, the frequency of oscillations decreased and eventually they ceased (continuation of traces, cont), with the membrane potential maintained at the hyperpolarized level. After washing out the blocker $(C)$, oscillations reappeared. For referencc, dotted lines in $A$ and $B$ indicate the same membrane potential level. Perfusion fluid contained 0.15 mM NMA and $3 \mu$ MTX throughout $A-C$, and the cell was constantly hyperpolarized with $-1.6 \mathrm{nA}$ of DC current. $D$ and $E$, Records from another neuron, in which upon removal of NMA $(E)$, oscillations decreased in frequency and amplitude before the membrane potential becanle flat at a hyperpolarized level. The cell was constantly injected with $-0.8 \mathrm{nA}$ hyperpolarizing current.

require activation of NMDA receptors, it became important to study whether the underlying mechanisms dcpend on the voltage-dependent properties of the NMDA-gated ionic channels, properties that are in turn attributed to a voltage-dependent blockade by magnesium ions (Mayer et al., 1984; Nowak et al., 1984; Mayer and Westbrook, 1985; cf. Moore et al., 1986). Experiments were therefore performed in which $\mathrm{Mg}^{2+}$ ions were removed from the perfusion medium, while recording from a neuron in the presence of NMDA and after TTX blockade. In normal, $\mathrm{Mg}^{2+}$-containing physiological solution $(1.8 \mathrm{mM})$, the cell in Figure 3 displayed large-amplitude oscillations without injection of DC current $(A)$; after 12 min of perfusion with $\mathrm{Mg}^{2+}$ free solution $(B)$, oscillation frequency had increased, and the large hyperpolarizing shifts disappeared, with the membrane potential fluctuating at the more depolarized level. Later (Fig. $3 B$ ), all oscillatory activity ceased, and the membrane potential remained stable at the level of the previous depolarized plateaus. After readministration of $\mathrm{Mg}^{2+}$ ions, partial recovery of the oscillations eventually occurred (Fig. 3C). To test whether the cessation of the oscillations upon removal of magnesium reflects a true $\mathrm{Mg}^{2+}$ ion dependence or is merely due to a potential shift outside the critical range for the oscillations, DC-current injections were made after the oscillations had disappeared in the $\mathrm{Mg}^{2+}$-free solution (Fig. 3D). Neither depolarizing nor hyperpolarizing current gave rise to any signs of oscillations. During oscillatory activity in the presence of $\mathrm{Mg}^{2+}$ ions, similar amounts of DC current strongly affected the oscillations (see Fig. 1). Thus, the NMDA-induced oscillations require the presence of physiological levels of magnesium ions.

In the lamprey spinal cord, fictive locomotion can also be induced by activation of kainate receptors (Brodin et al., 1985). There is no evidence that kainate receptor activation also induces TTX-resistant oscillations (Fig. 4). At a kainate concen- tration suitable to induce fictive locomotion in the absence of TTX (Brodin et al., 1985), no oscillations could be induced (Fig. $4 C$ ). The cell was hyper- and depolarized with several different strengths of DC current and was also injected with current pulses in order to try to evoke oscillatory behavior. This was, however, without effect. In contrast, the cell readily displayed oscillations in response to NMA before as well as after the test with kainate (Fig. 4, $A, E, F$ ).

\section{Ionic mechanisms}

The oscillatory membrane potential behavior thus appears to be due to an activation of voltage-dependent NMDA-receptors. At a certain membrane potential level the (TTX-resistant) ionic channels associated with the NMDA receptor will open and allow an inward current that will depolarize the cell.

Depolarizing phase. Two obvious candidate ionic species that could generate the depolarizing current are $\mathrm{Na}^{+}$and $\mathrm{Ca}^{2+}$ (Dingledine, 1983; Flatman et al., 1986). The possibility that $\mathrm{Na}^{+}$ is responsible was tested by substituting $\mathrm{Na}^{+}$with Tris in the perfusion medium. This caused a gradual reduction of the oscillation amplitude (Fig. 5, $A, B$ ), followed by a cessation of the oscillations (Fig. $5 C$ ). It is noteworthy that the membrane potential then remained at a more hyperpolarized level (dotted lines indicate the approximate control hyperpolarized potential level). When a $\mathrm{Na}^{+}$-containing physiological solution was again administered, the oscillations returned (Fig. $5 D$ ). $\mathrm{Na}^{+}$ions, entering through the NMDA-receptor-activated channels, thus appear to play a major role in the depolarizing phase of the oscillatory cycle. Removal of $\mathrm{Ca}^{2+}$ from the perfusion medium during ongoing oscillations will cause the membrane potential to remain at the depolarized plateaus for progressively longer periods of time and eventually be maintained at that level (Grillner and Wallén, 1985). Before the oscillations ceased, the de- 


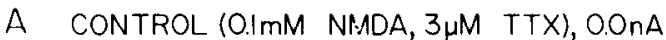

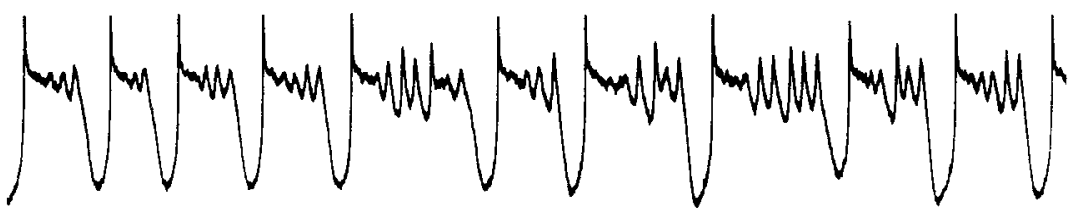

B Mg-FREE (I2 min), O.OnA

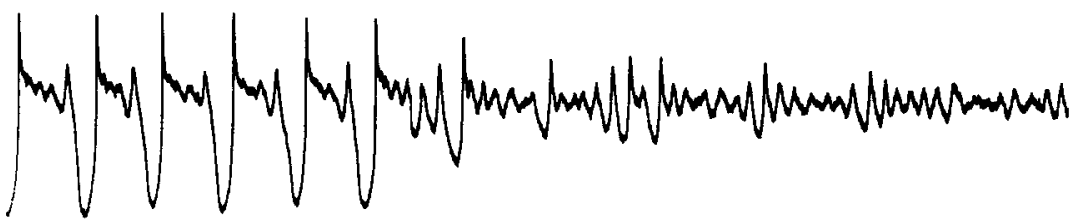

CONT

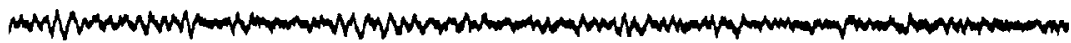

C RECOVERY (1.8mM Mg, $45 \mathrm{~min}), 0.0 \mathrm{nA}$

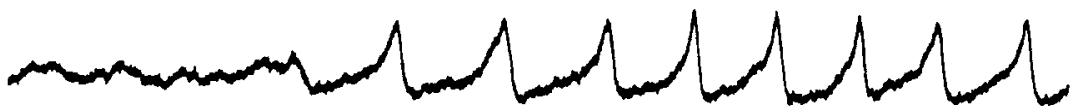

D Mg-FREE, DC-CURRENT INJECTION

$-0.2 n A$

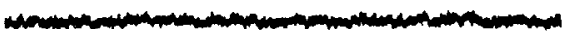

$2-0.5 n A$

2)

$3-0.8 n A$

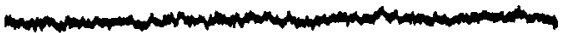

$4+0.2 n A$

4.

$5+0.5 n A$

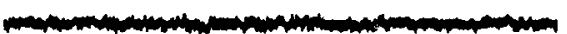

$6+0.8 n A$

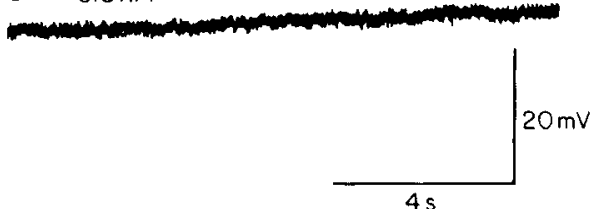

Figure 3. Effects of magnesium ion removal on the NMDA-induced oscillations. In normal physiological solution (containing $1.8 \mathrm{~mm} \mathrm{Mg}^{2+}$ and with $0.1 \mathrm{~mm}$ NMDA and $3 \mu \mathrm{M}$ TTX added), oscillatory activity occurred spontaneously without current injection $(A)$. Upon removal of $\mathrm{Mg}^{2+}$ ions $(B)$, oscillations increased in frequency and later disappeared (cont, direct continuation of trace above), with the membrane potential remaining stable at a depolarized level. At 45 min after readministration of $\mathrm{Mg}^{2+}$ ions $(C)$, oscillations reappeared, still without current injection. $D$, different amounts of DC current were injected into the same cell in the absence of $\mathrm{Mg}^{2+}$ ions. No oscillations could be elicited during either hyperpolarizing $(1-3)$ or depolarizing (4-6) current injection.

polarizing phase remained similar in form to the control situation. Neither the depolarization shift nor the maintained depolarization thus appears to depend on the presence of $\mathrm{Ca}^{2+}$, and thus $\mathrm{Ca}^{2+}$ cannot be the main carrier of the depolarizing current. Conventional $\mathrm{Ca}^{2+}$-channel blockers such as $\mathrm{Mn}^{2+}$ and $\mathrm{Co}^{2+}$ were not used, since they also interfere with ionophores activated by NMDA receptors (Ault et al., 1980).

The depolarizing phase is counteracted by an activation of voltage-dependent $\mathrm{K}^{+}$channels, since administration of tetraethyl ammonium will markedly enhance the amplitude of the depolarizing phase (Grillner and Wallén, 1985). This suggests that the peak level of the depolarization results from a balance between the depolarizing action of the NMDA-gated channels and the hyperpolarizing action of the voltage-dependent $\mathrm{K}^{+}$ channels, which will make the membrane potential stop at a certain plateau level before the fast repolarization starts.

Repolarizing phase. As described above, removal of $\mathrm{Ca}^{2+}$ prevents the repolarization in oscillatory cclls. This finding sug-

Figure 4. Comparative test of the ability of NMA and kainate in eliciting TTX-resistant oscillations. $A$, Under control conditions with $0.15 \mathrm{mM}$ NMA, the cell readily showed membrane potential oscillations when hyperpolarized with DC current $(-1.6 \mathrm{nA}) . B$, Upon washout of NMA, the cell hyperpolarized and oscillations ccascd. $C$, After addition of kainate $(20 \mu \mathrm{M})$, oscillations could not be elicited, although a variety of DC current levels as well as pulses were tested. When NMA was again tested, the recording became "unstable" at $-1.6 \mathrm{nA}$ DC current $(D)$, and the cell started to show oscillations when the current strength was increased only slightly $(-1.8 \mathrm{nA} ; E$ and $F$ ). Throughout $A-F$, solutions contained $3 \mu \mathrm{M}$ TTX. Time indications in $C-F$ are minutes after perfusion start of respective test solution. gests that the initial part of the repolarizing phase could be caused by the activation of $\mathrm{Ca}^{21}$-dependent $\mathrm{K}$ channels. To further investigate this possibility, $\mathrm{Ca}^{2+}$ was replaced with $\mathrm{Ba}^{2+}$ in the medium. $\mathrm{Ba}^{2+}$ will enter through $\mathrm{Ca}^{2+}$ channels, but it

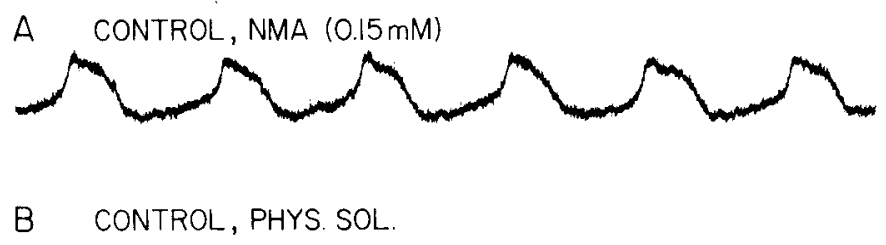

C KAINATE, $11 \mathrm{~min}(20 \mu \mathrm{M})$

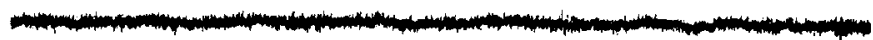

D NMA, $8 \mathrm{~min}(0.15 \mathrm{mM})$


F NMA, 16 min

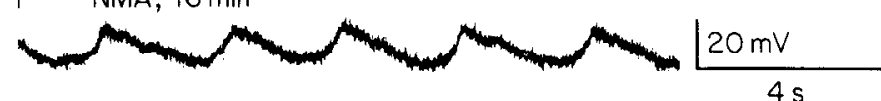




\section{A CONTROL (NMA $0.15 \mathrm{mM})$}
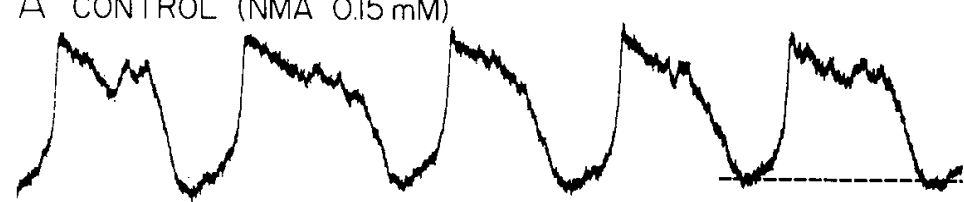

B $\mathrm{Na}$-FREE PHYS.SOL. $(3 \mathrm{~min})$

C Na-FREE PHYS. SOL. (CONT)


Figure 5. Effects of $\mathrm{Na}^{+}$removal on oscillatory activity. Under control conditions $(A)$, the cell showed normal, large membrane potential oscillations. Three minutes after starting to perfuse with $\mathrm{Na}^{+}$-free solution $(B)$, oscillations became smaller in amplitude and eventually disappeared $(C)$, with the membrane potential maintained at the hyperpolarized level. Horizontal dashed lines in $A-C$ indicate the same potential level. When Na+ was again added to the bath, oscillations returned $(D)$. Throughout $A-D$ the solutions contained 0.15 mM NMA and $3 \mu \mathrm{M}$ TTX. The cell was constantly injected with a negative DC current of $-1.1 \mathrm{nA}$ in $A-C$ and $-1.4 \mathrm{nA}$ in $D$.

will not activate the $\mathrm{Ca}^{2+}$-dependent $\mathrm{K}^{+}$channels (Meech, 1978; Hagiwara and Byerly, 1981). The effects of substituting $\mathrm{Ca}^{2+}$ with $\mathrm{Ba}^{2+}$ are shown in Figure 6 . In $\mathrm{Ba}^{2+}$-containing physiological solution, the depolarization peaks became longer (Fig. $6, A, B)$, and the depolarized plateau flatter. The oscillations eventually stopped, with the membrane potential remaining at the depolarized level (Fig. 6, C, D). These effects were essentially the same as those occurring upon $\mathrm{Ca}^{2+}$ removal (Grillner and Wallén, 1985). It should be noted that even when the cell remains at a constant depolarized level, the membrane potential can be shifted to a hyperpolarized stable level by a short-lasting hyperpolarizing current pulse (Grillner and Wallén, 1985). These results are thus in agreement with the suggestion that the repolarizing phase involves a $\mathrm{Ca}^{2+}$-dependent $\mathrm{K}^{+}$conductance.

\section{Role of oscillatory membrane properties during fictive locomotion}

Several characteristics of the TTX-resistant oscillations resemble the corresponding features of the membrane potential fluctuations during fictive locomotion (see General Characteristics, above), suggesting that oscillatory membrane properties might be operative during the generation of swimming. This was tested

A CONTROL (NMA $0.15 \mathrm{mM}$ )

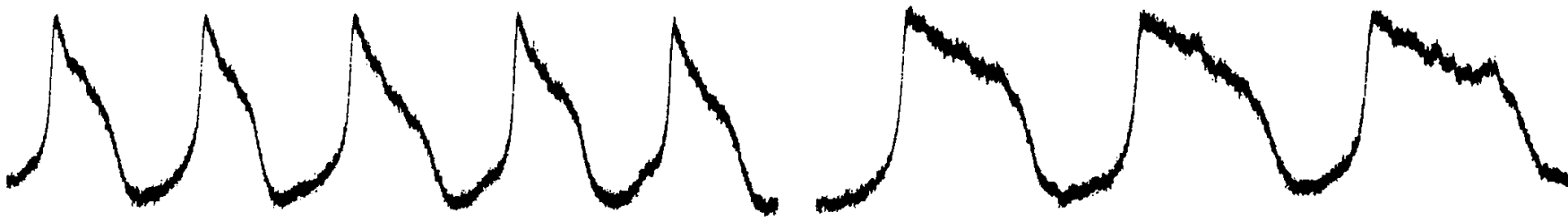

C $\mathrm{Ba}^{2 *}$ CONT.

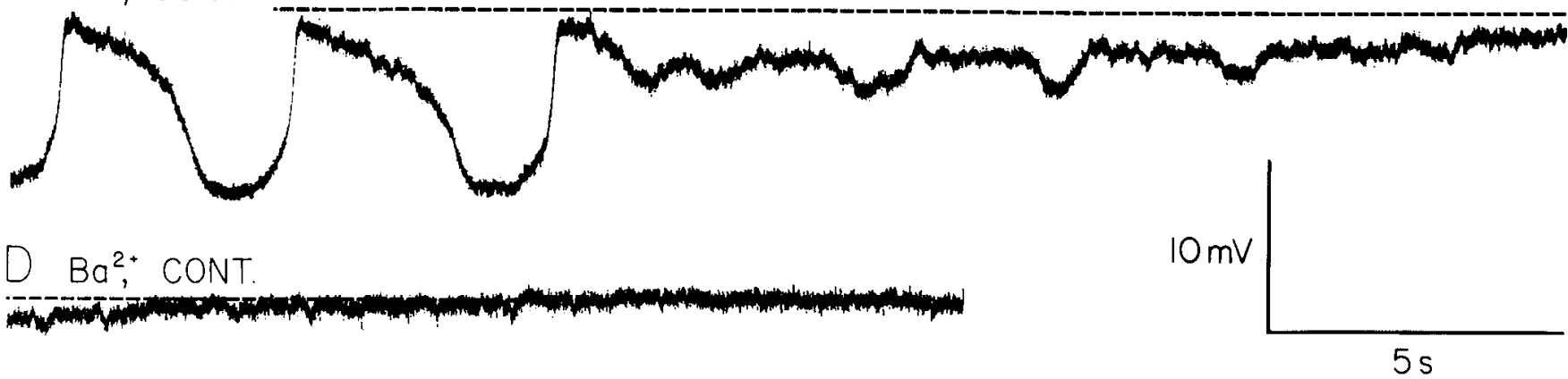

Figure 6. Experiment with $\mathrm{Ca}^{2+}$ removed and $\mathrm{Ba}^{2+}$ substituted. $A$, Control recording in normal physiological solution with NMA and TTX. When $\mathrm{Ba}^{2+}$ was substituted for $\mathrm{Ca}^{2+}$, depolarization peaks became broader $(B)$, and later oscillations stopped $(C)$, with the membrane potential remaining at the more depolarized level $(C$ and $D$ ). Dashed lines in $C$ and $D$ indicate the same potential level. Solutions contained 0.15 mM NMA and $3 \mu \mathrm{M}$ TTX throughout $A-D$. The cell was injected with a $-0.4 \mathrm{nA}$ DC current during the experiment. 
A $\quad+0.6 n A$

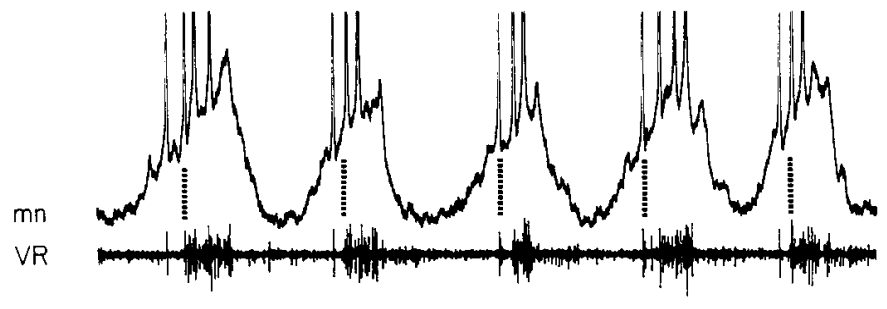

B $\quad 0.0 \mathrm{nA}$
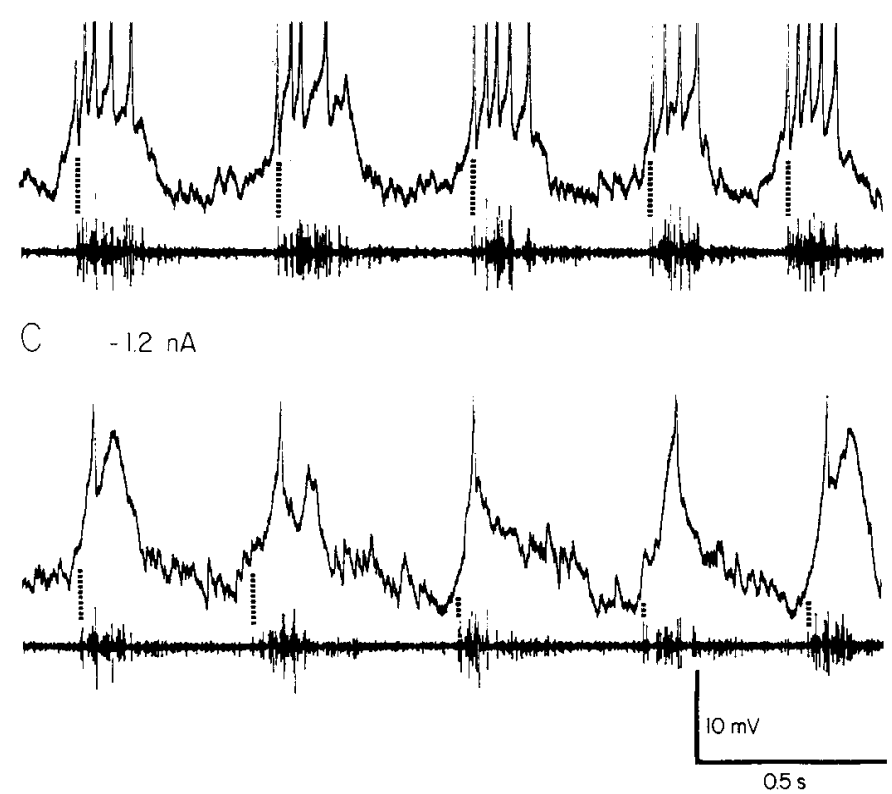

D HYPERPOL. PULSE

VR

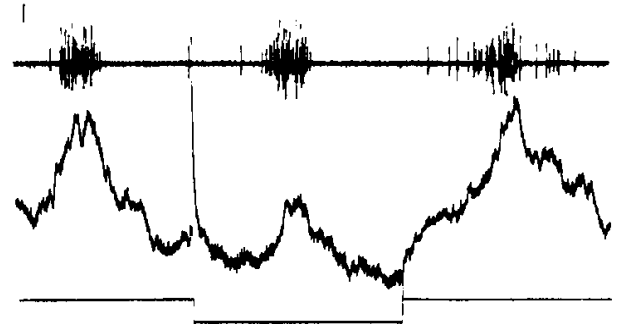

$-3.0 \mathrm{nA}$

2

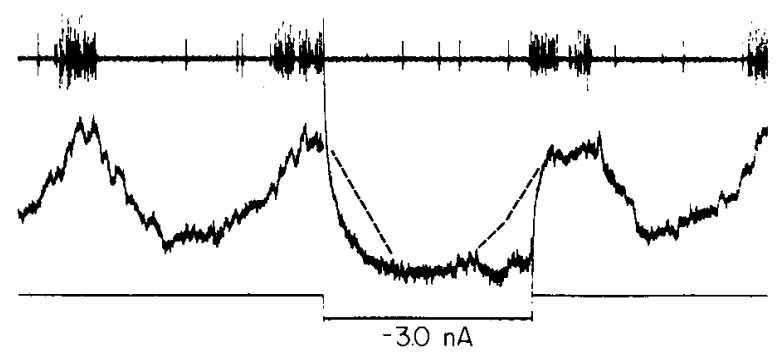

E DEPOL. PULSE

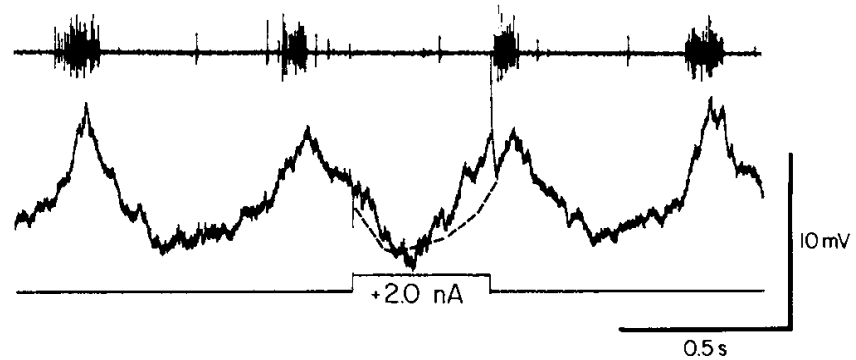

Figure 7. Intracellular current injection during fictive locomotor activity. $A-C$, Effects of constant current injection into a motoneuron ( $m n$ ). Interrupted vertical lines denote onset of the fictive locomotor burst in the ipsilateral ventral root $(V R)$ of the same segment. Depolarizing current $(A ;+0.6 \mathrm{nA})$ resulted in an earlier onset of the depolarization phase with respect to the burst activity, as compared to the control condition $(B$; no current). Hyperpolarizing current $(C ;-1.2 \mathrm{nA})$ resulted in a relatively later onset of the depolarization. During the interburst periods in $C$, some reversal of IPSPs occurred. The cell in $A-C$ was recorded with a Lucifer yellow-filled microelectrode (see Materials and Methods). $D$ and $E$, Effects of current pulse injection into another motoneuron. A hyperpolarizing pulse $(D ;-3.0 \mathrm{nA}, 600 \mathrm{msec})$ could decrease the size of a depolarizing peak $(I)$ or terminate and also delay the onset of the depolarization phase (2), depending on the timing of the stimulus pulse. Dashed lines (D:2 and $E)$ indicate approximate "normal" trajectory of the membrane potential. A positive current pulse $(E ;+2.0 \mathrm{nA}, 400 \mathrm{msec})$ instead augmented the depolarization phase. The neuron in $D$ and $E$ was recorded with a $\mathrm{K}$-acetate electrode. Throughout $A-E$, fictive locomotor activity was induced by bath application of $0.15 \mathrm{mM}$ NMA. Time and voltage calibration (intracellular traces) in $C$ applies to $A-C$ and that in $E$ applies to $D$ and $E$.

in experiments with intracellular current injection during fictive locomotion. Since the TTX-resistant oscillations are strongly dependent on the membrane potential level and are also influenced by injected current pulses (Wallén and Grillner, 1985), one would expect that intracellular stimulation during fictive locomotion might perturb the activity pattern in a way predicted by the results from the same kind of stimuli delivered during TTX blockade. Figure 7, $A-C$, illustrates an experiment in which a motoneuron was injected with constant depolarizing $(A)$ or hyperpolarizing current $(C)$. The changes in shape of the potential fluctuations compared to the control condition (Fig. $7 B$ ) are cvident. When the cell was depolarized (Fig. 7A), the onset of the depolarization occurred earlier with respect to the ventral root burst (note vertical interrupted lines, see Fig. 7B). Hyperpolarizing DC current resulted in later onset of the depolarization peak (Fig. 7C). These results are not readily explained if the membrane potential oscillations were due to synaptic input alone but would be compatible with voltage-dependent membrane properties being involved in the formation of the oscillatory wave (see above; Fig. 1). By adding TTX after these records were taken, it was confirmed that this neuron displayed inherent membrane potential oscillations (not illustrated). In Figure $7, D, E$, the effects from intracellular pulse stimulation during fictive locomotor activity are shown in another cell. A hyperpolarizing pulse given during the phase of depolarization can reduce the size of the depolarizing peak (Fig. $7 D: 1$ ), and if delivered somewhat later in the cycle, it can terminate the depolarization prematurely and also delay the onset of the following depolarization (Fig. 7D:2). Conversely, a depolarizing pulse can instead augment the depolarization phase (Fig. $7 E$ ). These effects would also be compatible with an involvement of voltagedependent membrane properties.

The interpretation of these findings was further corroborated in experiments with $\mathrm{Mg}^{2+}$-free solution, in which the voltagedependent properties should not be operative (see above). The neuron of Figure 8 was tested in ordinary physiological solution $(A)$ with DC-current injection and also in $\mathrm{Mg}^{2+}$-free solution $(B)$. In Figure $8 A$ the change in shape of the oscillations is evident, as is the earlier onset of the depolarization during positive current injection (Fig. 8A:1) and the later onset during 

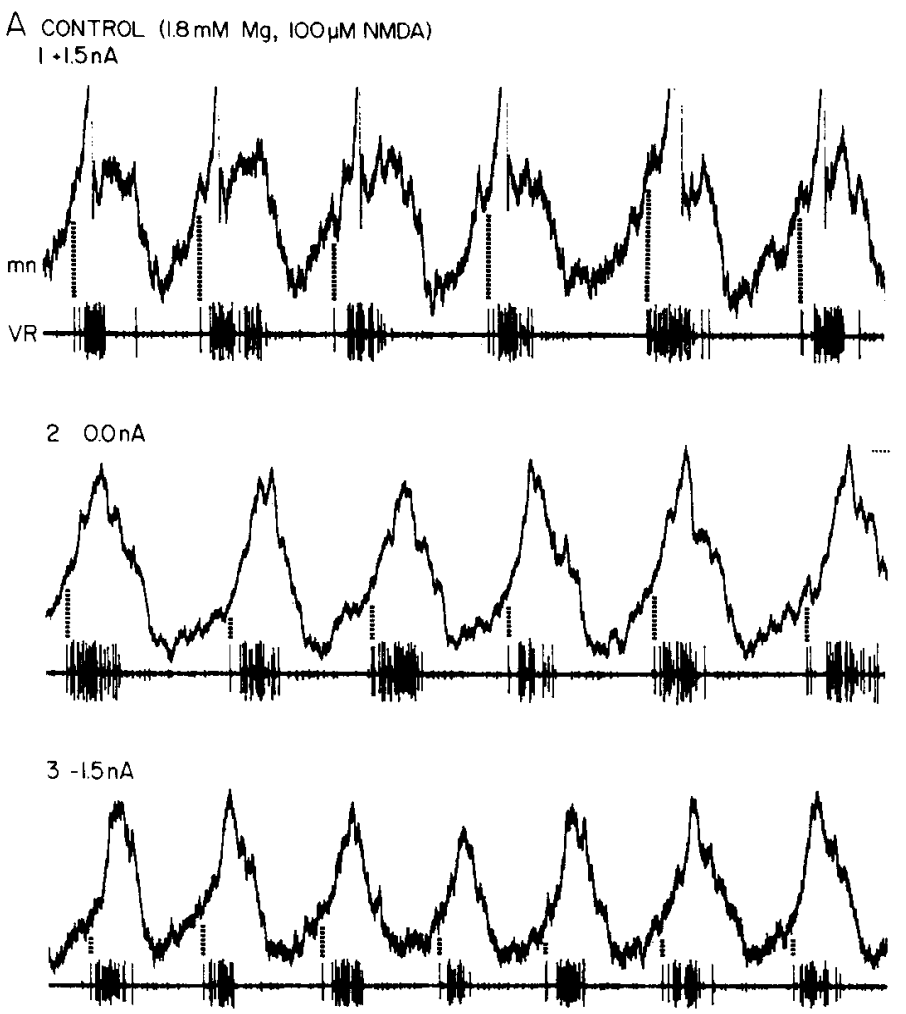

B Mg-FREE (IO $\mu M$ NMDA)

$$
1+1.5 \mathrm{nA}
$$

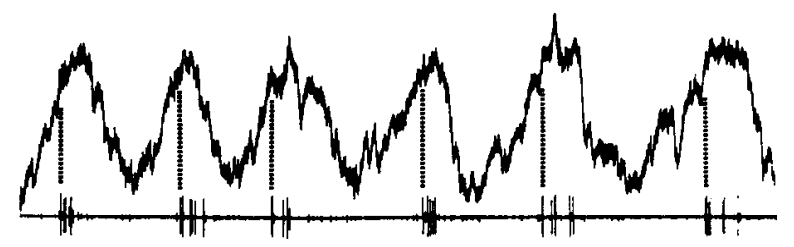

$20.0 \mathrm{nA}$
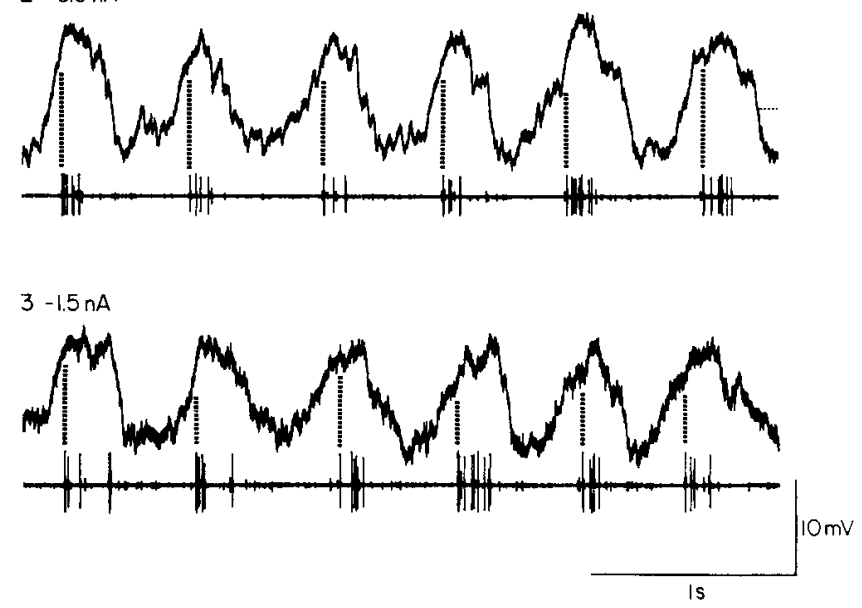

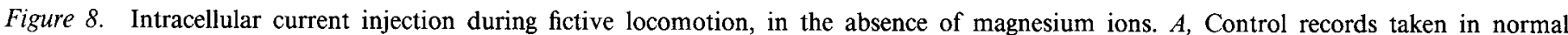

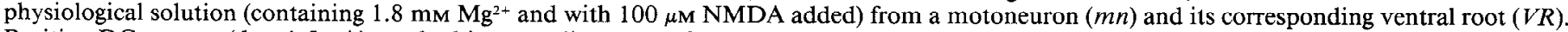

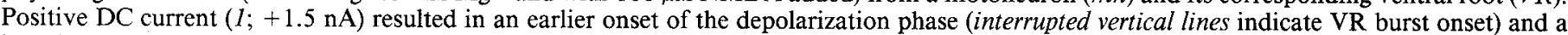

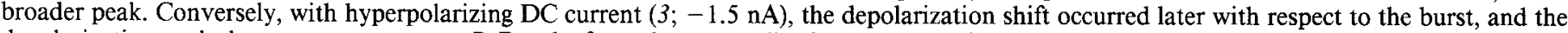

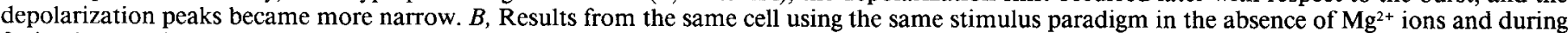

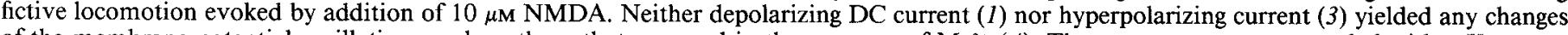

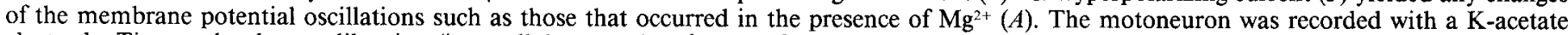
electrode. Time and voltage calibration (intracellular traces) at lower right applies to all records.

hyperpolarizing DC current (Fig. 8A:3). After removal of $\mathrm{Mg}^{2+}$ ions fictive locomotor activity can still be produced, but since the blocking action of $\mathrm{Mg}^{2+}$ is no longer present, the threshold dose of NMDA is substantially lowered (Brodin and Grillner, 1986; Fig. $8 B$ ). In $\mathrm{Mg}^{2+}$-free solution, the neuron in Figure 8 displayed rather regular oscillatory activity at a similar rate with a 10th of the NMDA dose (Fig. $8 B$ ) compared with the control situation with magnesium (Fig. $8 A$ ). In addition, the ventral root activity is weaker and less regular in the absence of $\mathrm{Mg}^{2+}$ (see Brodin and Grillner, 1986). In $\mathrm{Mg}^{2+}$-free solution, DCcurrent injection clearly did not produce the effects described above on the oscillatory pattern of the cell (Fig. $8 B$ ). There was no consistent change either in oscillation shape or in timing of depolarization onset relative to the ventral root burst (Fig. 8 , $B: 1-3)$. Thus, the voltage-dependent gating of the NMDA-receptor channels appears responsible for the described effects on the oscillatory activity (see Discussion).

\section{Occurrence of oscillatory membrane properties in different types of neurons}

Recordings were made from several types of identified neurons in order to estimate the distribution of oscillatory membrane properties among neuronal classes. Of the 156 neurons tested to date, 67 were identified morphologically and/or physiologically (see Materials and Methods). The results are summarized in Table 1. The majority of identified and tested motoneurons showed oscillatory activity in TTX. CC interneurons and many unclassified interneurons are also able to generate TTX-resistant oscillations. However, when testing lateral interneurons, dorsal cells, and edge cells (Rovainen, 1979; Grillner et al., 1984), none could be made to produce the oscillations.

As demonstratcd above (Fig. 2), the occurrence of TTX-resistant oscillations depends on NMDA-receptor activation. Such activation also causes a general depolarization of the cell. A quantitative study of the depolarizing response to NMDA-receptor activation has not been performed in oscillatory neurons, but in one motoneuron that showed TTX-resistant oscillations, the net hyperpolarization following removal of NMA $(150 \mu \mathrm{M})$ was estimated to be about $15 \mathrm{mV}$. Dorsal cells (3/3) and edge

\begin{tabular}{ll}
\hline $\begin{array}{l}\text { Table 1. Summary of results from identified neurons tested for } \\
\text { oscillatory activity in TTX }\end{array}$ \\
Cell type & Oscillations in TTX \\
\hline Motoneurons & $+(28 / 38)$ \\
CC interneurons & $+(3 / 5)$ \\
Unclassified interneurons & $+(4 / 4)$ \\
Edge cells & $-(0 / 7)$ \\
Dorsal cells & $-(0 / 6)$ \\
Lateral interneurons & $-(0 / 7)$ \\
\hline
\end{tabular}

TTX-resistant oscillations were demonstrated in some cell types (+) but not in others $(-)$. The number of oscillating cells among the tested cells is indicated in parentheses. 


\section{NMDA induced TTX-resistont oscillations}

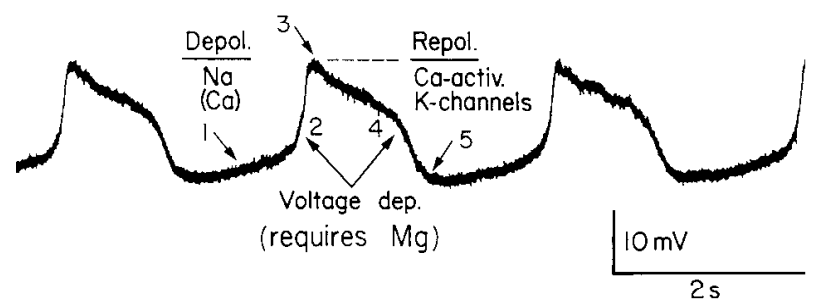

Figure 9. Schematic representation of some factors contributing to the NMDA-receptor-induced, TTX-resistant membrane potential oscillations in lamprey neurons (see text).

cells (3/4) did not change their level of membrane potential when NMA (150-300 $\mu \mathrm{M})$ was administered; presumably, therefore, they have no or few NMDA receptors. One edge cell was depolarized by $2 \mathrm{mV}$ by NMA.

\section{Discussion}

\section{Ionic mechanisms of TTX-resistant membrane potential oscillations}

The membrane potential oscillations seen in a significant proportion of neurons in the lamprey spinal cord after TTX blockade clearly require an activation of NMDA receptors. Not only do the oscillations disappear when the agonist (NMA) is removed, but also upon specific NMDA receptor blockade (Fig. 2 ). This blockade leaves the membrane potential at a more hyperpolarized level, showing that the activation of NMDA receptors gives rise to a depolarizing current during TTX blockade also. If one assumes that the degree of depolarization reflects the density of NMDA receptors on a given cell, it appears likely (Table 1) that the ability to produce TTX-resistant oscillations is related to the NMDA-receptor density. In edge cells, dorsal cells, and lateral interneurons - in which oscillations could not be evoked - the density of NMDA receptors would appear to be low. It would thus seem important to establish whether the depolarizing action of NMDA in known concentrations varies between different cells and whether this action is correlated to the ability to produce oscillations. Obviously the blend of other types of membrane channels in a given neuron will also influence the responsiveness of the cell.

The fact that the membrane potential starts to oscillate between 2 levels suggests that bistable membrane properties are brought into action. Indeed, using voltage clamp it has recently been demonstrated that NMDA application induces a region of negative slope conductance in lamprey oscillatory neurons also (Moore et al., 1986; cf. MacDonald et al., 1982; Flatman et al., 1983, 1986), which is likely to reflect the voltage-dependent block by $\mathrm{Mg}^{2+}$ ions. Accordingly, removal of $\mathrm{Mg}^{2+}$ makes the oscillatory activity cease (Fig. 3). During $\mathrm{Mg}^{2+}$ ion removal, the decreasing blocking action on the NMDA-gated channels presumably accounts for the initial increase in oscillation amplitude and frequency. In the absence of magnesium, the blockade of the NMDA-gated channels is removed with the channels remaining open, leading to a nonoscillating membrane potential maintained in a depolarized state (Fig. $3 B$ ). The voltage-dependence of the oscillations is further corroborated by the finding of a strong correlation between oscillation frequency and the membrane potential level (Fig. 1).
It is generally assumed that the depolarizing current following NMDA-receptor activation is primarily carried by $\mathrm{Na}^{+}$ions (see Mayer and Westbrook, 1987). Recent data show that both $\mathrm{Ca}^{2+}$ and $\mathrm{Na}^{+}$ions will pass through the NMDA ionophore but that $\mathrm{Na}^{+}$ions will dominate and carry most of the current (MacDermott et al., 1986). Our results suggest that $\mathrm{Na}^{+}$is the major carrier in the case of lamprey neurons also. Since $\mathrm{Ca}^{2+}$ removal does not significantly affect the depolarizing trajectory (Grillner and Wallén, 1985), a contribution from $\mathrm{Ca}^{2+}$ ions would presumably be small. The repolarization phase, on the other hand, appears to require the presence of $\mathrm{Ca}^{2+}$ ions, which suggests that $\mathrm{Ca}^{2+}$ ions also in lamprey actually are transmitted through the NMDA ionophore. It also suggests that $\mathrm{Ca}^{2+}$-dependent $\mathrm{K}^{+}$ channels could contribute to the repolarization. The results obtained when $\mathrm{Ca}^{2+}$ was substituted with $\mathrm{Ba}^{2+}$ corroborates this suggestion, since $\mathrm{Ba}^{2+}$, while replacing $\mathrm{Ca}^{2+}$ in $\mathrm{Ca}^{2+}$ channels, and presumably also in NMDA-gated channels, will not activate the $\mathrm{Ca}^{2+}$-dependent $\mathrm{K}^{+}$channels (Meech, 1978; Hagiwara and Byerly, 1981). The ionic events during the NMDA-receptorinduced membrane potential oscillations can then be summarized as follows (Fig. 9): Under the influence of NMDA, the membrane potential will depolarize (1), until a level is reached at which the voltage-dependent blockade by $\mathrm{Mg}^{2+}$ of the NMDAgated channels is markedly reduced, leading to a fast regenerative depolarization (2). The depolarizing current is mainly carried by $\mathrm{Na}^{+}$. At this point, a TEA-sensitive $\mathrm{K}^{+}$current will partly counteract the depolarization (Grillner and Wallén, 1985), and a plateau will be reached (3). $\mathrm{Ca}^{2+}$-dependent $\mathrm{K}^{+}$channels, activated by a gradual accumulation of $\mathrm{Ca}^{2+}$ entering through the NMDA-gated channels during the depolarization, will then hyperpolarize the membrane until a level is reached (4), at which the NMDA-gated channels will close due to a return of the voltage-dependent block; the membrane potential will then rapidly repolarize to the hyperpolarized level (5). Since no new $\mathrm{Ca}^{2+}$ will enter through the closed NMDA channels, the intracellular $\mathrm{Ca}^{2+}$ level will decrease and thus also the number of $\mathrm{Ca}^{2+}$-activated $\mathrm{K}^{+}$channels, leading to a gradual depolarization. When the depolarization reaches the threshold for the voltagedependent gating of the NMDA channels, a new cycle will start. This scheme could thus account for the main features of the observed oscillatory behavior. However, additional contributing mechanisms can certainly not be excluded at present. Further voltage-clamp studies are needed in order to get more quantitative information about the underlying ionic currents.

\section{Possible functional significance}

The results presented show that a selective activation of NMDA receptors by bath application of the agonist can give rise to pacemakerlike potentials when TTX has been administered. During fictive locomotion induced by application of NMA at the same low concentration, presumably giving rise to an activation of a similar number of NMDA channels on the neurons, the motor pattern is coordinated by phasic synaptic potentials. The synaptically driven membrane potential oscillations also appear to involve voltage-dependent properties of NMDA channels under these conditions (Figs. 7, 8), since they are affected by DC shifts, current pulses, and removal of $\mathrm{Mg}^{2+}$ ions in an analogous way to that found with the pacemakerlike potentials observed after TTX.

However, locomotion is not normally induced by bath application of excitatory amino acids, but rather by descending or sensory pathways, both of which utilize excitatory amino acid 
transmission (Brodin and Grillner, 1985a; Christenson et al., 1986; Brodin et al., 1987; see Grillner et al., 1987a), as do the excitatory premotor interneurons used during fictive locomotion (Buchanan and Grillner, 1987). The membrane potential oscillations elicited by premotor interneurons in motoneurons depend on both kainate and NMDA-receptor activation (Dale, 1986; Dale and Grillner, 1986). The relative role of the voltage dependence of the NMDA channels in contrast to the nonNMDA-mediated EPSPs remains to be elucidated. Previous studies with recordings of the motor pattern suggest that an NMDA-receptor activation in the presence of magnesium is of particular importance to maintain a slow, steady rate of swimming (Brodin and Grillner, 1985a, 1986), whereas faster swimming can occur also after a blockade of NMDA receptors. Voltage-clamp studies are in progress to investigate further the role of the voltage dependence of the NMDA channels during fictive locomotion (Moore et al., 1987).

\section{References}

Ault, B., R. H. Evans, A. A. Francis, D. J. Oakes, and J. C. Watkins (1980) Selective depression of excitatory amino acid induced depolarizations by magnesium ions in isolated spinal cord preparations. J. Physiol. (Lond.) 307: 413-428.

Brodin, L., and S. Grillner (1985a) The role of putative excitatory amino acid neurotransmitters in the initiation of locomotion in the lamprey spinal cord. I. The effects of excitatory amino acid antagonists. Brain Res. 360: 139-148.

Brodin, L., and S. Grillner (1985b) The role of putative excitatory amino acid neurotransmitters in the initiation of locomotion in the lamprey spinal cord. II. The effects of amino acid uptake inhibitors. Brain Res. 360: 149-158.

Brodin, L., and S. Grillner (1986) Effects of magnesium on fictive locomotion induced by activation of $\mathrm{N}$-methyl-D-aspartate (NMDA) receptors in the lamprey spinal cord in vitro. Brain Res. 380: 244252.

Brodin, L., S. Grillner, and C. M. Rovainen (1985) NMDA, kainate and quisqualate receptors and the generation of fictive locomotion in the lamprey spinal cord. Brain Res. 325: 302-306.

Brodin, L., J. Christenson, and S. Grillner (1987) Single sensory neurons activate excitatory amino acid receptors in the lamprey spinal cord. Neurosci. Lett. 75: 75-79.

Buchanan, J. T. (1982) Identification of interneurons with contralateral, caudal axons in the lamprey spinal cord: Synaptic interactions and morphology. J. Neurophysiol. 47: 961-975.

Buchanan, J. T., and A. H. Cohen (1982) Activities of identified interneurons, motoneurons, and muscle fibers during fictive swimming in the lamprey and cffects of reticulospinal and dorsal cell stimulation. J. Neurophysiol. 47: 948-960.

Buchanan, J. T., and S. Grillner (1987) Newly identified "glutamate interneurons" and their role in locomotion in the lamprey spinal cord. Science 236: 312-314.

Christenson, J., L. Brodin, J. Buchanan, N. Dale, and S. Grillner (1986) Sensory afferent and descending fiber mediated excitation of lamprey spinal neurones; effects of excitatory amino acid antagonists. Neurosci. Lett. Suppl. 26: S161.

Dale, N. (1986) Excitatory synaptic drive for swimming mediated by amino acid receptors in the lamprey. J. Neurosci. 6: 2662-2675.

Dale, N., and S. Grillner (1986) Dual-component synaptic potentials in the lamprey mediated by excitatory amino acid receptors. J. Neurosci. 6: 2653-2661.

Davies, J., and J. C. Watkins (1983) Rolc of excitatory amino acid receptors in mono- and polysynaptic excitation in the cat spinal cord. Exp. Brain Res. 49: 280-290.

Davies, J., A. A. Francis, A. W. Jones, and J. C. Watkins (1981) 2-Amino-5-phosphonovalerate (2-APV), a potent and selective antagonist of amino acid induced and synaptic excitation. Neurosci Lett. 21: 77-81.

Dingledine, R. (1983) N-methyl aspartate activates voltage-dependent calcium conductance in rat hippocampal pyramidal cells. J. Physiol. (Lond.) 343: 385-405.

Flatman, J. A., P. C. Schwindt, W. E. Crill, and C. E. Stafstrom (1983)
Multiple actions of $\mathrm{N}$-methyl-D-aspartate on cat neocortical neurons in vitro. Brain Res. 266: 173-189.

Flatman, J. A., P. C. Schwindt, and W. E. Crill (1986) The induction and modification of voltage-sensitive responses in cat neocortical neurons by N-methyl-D-aspartate. Brain Res. 363: 62-77.

Getting, P. A. (1986) Understanding central pattern generators: Insights gained from the study of invertebrate systems. In Neurobiology of Vertebrate Locomotion, S. Grillner, P. S. G. Stein, D. G. Stuart, H. Forssberg, and R. M. Herman, eds., pp. 231-244, MacMillan, London.

Grillner, S., and P. Wallén (1985) The ionic mechanisms underlying $\mathrm{N}$-methyl-D-aspartate receptor-induced, tetrodotoxin-resistant membrane potential oscillations in lamprey neurons active during locomotion. Neurosci. Lett. 60: 289-294.

Grillner, S., A. McClellan, K. Sigvardt, P. Wallén, and M. Wilén (1981) Activation of NMDA-receptors elicits "fictive locomotion" in lamprey spinal cord in vitro. Acta Physiol. Scand. 113: 549-551.

Grillner, S., T. Williams, and P.- $\AA$. Lagerbäck (1984) The edge cell, a possible intraspinal mechanoreceptor. Science 223: 500-503.

Grillner, S., L. Brodin, J. T. Buchanan, P. Wallén, N. Dale, R. Hill, and L. E. Moore (1987a) Excitatory amino acid transmission in the lamprey spinal cord-a key role in the generation of locomotion. In Excitatory Amino Acid Transmission, T. P. Hicks, D. Lodge, and H. McLennan, eds., pp. 293-300, Liss, New York.

Grillner, S., P. Wallén, N. Dale, L. Brodin, J. Buchanan, and R. Hill (1987b) Transmitters, membrane properties and network circuitry in the control of locomotion in lamprey. Trends Neurosci. 10:34 41 .

Hagiwara, S., and L. Byerly (1981) The calcium channel. Annu. Rev. Neurosci. 4: 69-125.

Kristan, W. B., and J. C. Weeks (1983) Neurons controlling the initiation, generation and modulation of leech swimming. In Neural Origin of Rhythmic Movements, A. Roberts and B. L. Roberts, eds., pp. 243-260, Cambridge U. P., Cambridge.

MacDermott, A. B., M. L. Mayer, G. L. Westbrook, S. J. Smith, and J. L. Barker (1986) NMDA-receptor activation increases cytoplasmic calcium concentration in cultured spinal cord neurones. Nature 321: 519-522.

MacDonald, J. F., A. V. Porietis, and J. M. Wojtowicz (1982) $\mathrm{L}$-aspartic acid induces a region of negative slope conductance in the current-voltage relationship of cultured spinal neurons. Brain Res. 237: 248-253.

Mayer, M. L., and G. L. Westbrook (1984) Mixed-agonist action of excitatory amino acids on mouse spinal cord neurones under voltage clamp. J. Physiol. (Lond.) 354: 29-53.

Mayer, M. L., and G. L. Westbrook (1985) The action of N-methylD-aspartic acid on mouse spinal neurones in culture. J. Physiol. (Lond.) 361: 65-90.

Mayer, M. L., and G. L. Westbrook (1987) The physiology of excitatory amino acids in the vertebrate central nervous system. Prog. Neurobiol. 28: 197-276.

Mayer, M. L., G. L. Westbrook, and P. B. Guthrie (1984) Voltagedependent block by $\mathrm{Mg}^{2+}$ of NMDA responses in spinal cord neurones. Nature 309:261-263.

Meech, R. W. (1978) Calcium-dependent potassium activation in nervous tissues. Annu. Rev. Biophys. Bioeng. 7: 1-18.

Moore, L. E., R. H. Hill, and S. Grillner (1986) Voltage-clamp analysis of NMDA induced oscillating spinal neurons. Acta Physiol. Scand. 128: 20A.

Moore, L. E., R. H. Hill, and S. Grillner (1987) Frequency domain voltage clamp analysis of NMDA receptor activated spinal neurones in lamprey. Acta Physiol. Scand. 129: 10A.

Nowak, L., P. Bregetovski, P. Ascher, A. Herbet, and A. Prochiantz (1984) Magnesium gates glutamate-activated channels in mouse central neurones. Nature 307: 462-465.

Roberts, A., S. R. Soffe, and N. Dale (1986) Spinal interneurones and swimming in frog embryos. In Neurobiology of Vertebrate Locomotion, S. Grillner, P. S. G. Stein, D. G. Stuart, H. Forssberg, and R. M. Herman, eds., pp. 279-306, MacMillan, London.

Rovainen, C. M. (1979) Neurobiology of lampreys. Physiol. Rev. 59: 1007-1077.

Russell, D. F., and P. Wallén (1980) On the pattern generator for fictive swimming in the lamprey, Ichthyomyzon unicuspis. Acta Physiol. Scand. 108:9A.

Russell, D. F., and P. Wallén (1983) On the control of myotomal 
motoneurones during "fictive swimming" in the lamprey spinal cord in vitro. Acta Physiol. Scand. 117: 161-170.

Selverston, A. I., and M. Moulins (1985) Oscillatory neural networks. Annu. Rev. Physiol. 47: 29-48.

Sigvardt, K. A., and S. Grillner (1981) Spinal neuronal activity during fictive locomotion in the lamprey. Soc. Neurosci. Abstr. 7: 362.

Sigvardt, K. A., S. Grillner, P. Wallên, and P. A. M. van Dongen (1985) Activation of NMDA receptors elicits fictive locomotion and bistable membrane properties in the lamprey spinal cord. Brain Res. 336: 390-395.

Smith, T. G. Jr., J. L. Barker, and H. Gainer (1975) Requirements for bursting pacemaker potential activity in molluscan neurones. $\mathrm{Na}$ ture 253: 450-452.

Stewart, W. W. (1978) Functional connections between cells as re- vealed by dye coupling with a highly fluorescent naphthalimide tracer. Cell 14: 741-759.

Wallén, P., P. Grafe, and S. Grillner (1984) Phasic variations of extracellular potassium during fictive swimming in the lamprey spinal cord in vitro. Acta Physiol. Scand. 120: 457-463.

Wallén, P., and S. Grillner (1985) The effect of current passage on $\mathrm{N}$-methyl-D-aspartate-induced, tetrodotoxin-resistant membrane potential oscillations in lamprey neurons active during locomotion. Neurosci. Lett. 56: 87-93.

Wallén, P., S. Grillner, J. L. Feldman, and S. Bergelt (1985) Dorsal and ventral motoneurons and their input during fictive locomotion in the lamprey. J. Neurosci. 5: 654-661.

Watkins, J. C., and R. H. Evans (1981) Excitatory amino acid transmitters. Annu. Rev. Pharmacol. Toxicol. 21: 165-204. 